\title{
Secondary School Curriculum in The First Decade of Independence in Kenya: A Case of Friend's School Kamusinga
}

Pius W Muricho, Emmy Kipsoi and Kefa L. Simwa

To Link this Article: http://dx.doi.org/10.6007/IJARBSS/v11-i9/11143

DOI:10.6007/IJARBSS/v11-i9/11143

Received: 13 July 2021, Revised: 10 August 2021, Accepted: 30 August 2021

Published Online: 18 September 2021

In-Text Citation: (Muricho et al., 2021)

To Cite this Article: Muricho, P. W., Kipsoi, E., \& Simwa, K. L. (2021). Secondary School Curriculum in The First Decade of Independence in Kenya: A Case of Friend's School Kamusinga. International Journal of Academic Research in Business and Social Sciences, 11(9), 1318-1331.

Copyright: @ 2021 The Author(s)

Published by Human Resource Management Academic Research Society (www.hrmars.com)

This article is published under the Creative Commons Attribution (CC BY 4.0) license. Anyone may reproduce, distribute, translate and create derivative works of this article (for both commercial and non-commercial purposes), subject to full attribution to the original publication and authors. The full terms of this license may be seen at: http://creativecommons.org/licences/by/4.0/legalcode

Vol. 11, No. 9, 2021, Pg. 1318 - 1331

Full Terms \& Conditions of access and use can be found at http://hrmars.com/index.php/pages/detail/publication-ethics 


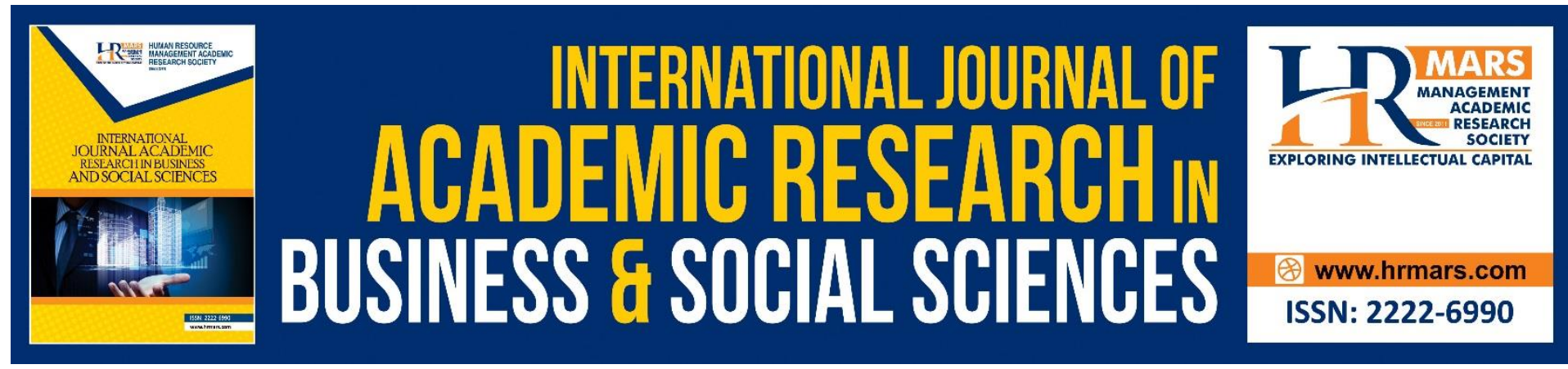

\title{
Secondary School Curriculum in The First Decade of Independence in Kenya: A Case of Friend's School Kamusinga
}

\author{
Pius W Muricho, Emmy Kipsoi and Kefa L. Simwa \\ Department of Education Foundations, Moi University P.O. Box 3900, Eldoret, Kenya
}

\begin{abstract}
The Ominde Education Reports (1964) commissioned in the first decade of independence in Kenya provide important policy direction on educational developments at the secondary school level yet scholarly historical accounts on this phenomenon are scanty. This paper explores the implementation of the secondary school curriculum proposed by the Ominde Education Commission (1964) at Friends School Kamusinga in Kenya's first decade of independence. The study adopted a historical research design. The study used Trevor Gale's (2001) Theoretical Framework of Critical Policy Archaeology and historical thinking conceptual framework by Seixas (2006) to examine concepts of historical significance, change and continuity in the reform process. Data collection involved a critical review of relevant literature; including several curriculum reforms documents and oral interviews. Snowball sampling was adopted to select 12 participants. Data analysis and interpretation were done through internal and external historical criticism. Based on the literature review and documentary analysis, there was overwhelming evidence for Kenya to review education at independence since Kenyan education has its roots in the colonial past. The Government formed several Commissions to carry out major reforms in education in response to the changing needs of the Kenyan society. The findings showed that FSK, both "O" level and A level subjects were offered. For the "O" level, the subjects included Languages (English and Kiswahili), Mathematics, Humanities and Sciences. At " $A$ " level, both Arts and Science subjects and General Paper were offered. In the formative years of FSK, there was heavy reliance on foreign teachers from FAM Missions, TEA, BEA, Peace Corps in the implementation of the curriculum. Teacher effort was complemented by curriculum materials originated from the KIE and requisite systematic MOE administrative activities through its inspectorate division. At FSK students performed well in end of cycle national examinations. The implementation of curriculum at FSK influenced curriculum roll out in upcoming neighbouring schools. Overall, findings showed that the enactment of the secondary school curriculum policy in the FSK reflect the aspirations of the Ominde Report. The study concludes that education system proposed by OEC was implemented at FSK and other schools in Kenya. The implementation was a continuation of the colonial British curriculum fashioned towards European culture and values. The development and implementation of the curriculum was a top-down policy which excluded teachers and parents. the study recommends that there is need to improve our curriculum policy (but caution should be taken especially with imported education policies
\end{abstract}


and ideologies/values. This study recommends that the government should thoroughly invest in researching on curriculum policies to determine their suitability rather than adopting foreign ones which could be irrelevant to the society needs.

Keywords: Education, Curriculum, Curriculum Implementation, Commission.

\section{Introduction}

Kivuva (2000) points out that the role of Education can be summarized as assisting in the establishment of the human resource base for the generation of wealth and more importantly, its application for the creative of a higher standard of living and improved quality of life. Therefore, education was viewed as a productive investment both to the individual and the society. Sadly, during the colonial regime, Kenyans, as other Africans, experienced great discrimination economically, academically, socially and politically (Bogonko, 1992; Otiende et al., 1992)

This paper discusses how secondary school subjects were implemented at Friends School Kamusinga (FSK) between 1964 and 1974. Its concern is hinged on education reforms characterized and influenced by the post-independence recommendation of the Ominde Education Commission (OEC hear after) in 1964. This was the first education commission in the independent Kenya.

Before 1950, there were only $50(G O K, 1949)$ secondary schools, but due to the Harambee school movement and African agitation for academic curriculum and higher education secondary schools expanded due to high enrolments in primary schools (GOK, 1964). According to Nabiswa (1996), FSK Kamusinga was established at the present site by Friends African Mission (FAM) in 1957. The school stands on 55 acres of land, $2 \mathrm{1} / 2 \mathrm{Km}$ from Kimilili Town on the slopes of Mount Elgon (Inspection Reports, 1981 and 1973).

Friends School Kamusinga was started during the colonial era, 1957. For a better understanding on the transition of education curriculum that would suit Africans at independence, an institution that was started during the colonial period would give relevant and reliable picture because the school has enough sources of data for historical analysis as per the guidance of Golder (2000).

For this reason, FSK was purposely selected for the study since it has data that would cut across the two epochs: the colonial and post-colonial times. Again, FSK was among the key schools in then the Western Province of Kenya that FAM Missions and the colonial government had put much resource to implement secondary school curriculum. Since decolonization and Kenya's independence, FSK has been the best performing school in the present Bungoma County. In view of this, there was need to study secondary school curriculum in the first decade of independence in Kenya focusing on Friend's School Kamusinga. This would aid in understanding trends of curriculum reforms in Kenya so as to avoid certain pitfalls that could derail efforts of CBC curriculum reforms in the country. The findings of the study would also help in identifying certain strengths and weaknesses. That is, the weaknesses to be avoided, whereas strength could be embraced in a bid to come up with sustainable implementation of curriculum reforms in Kenya.

\section{Theoretical, Conceptual and Methodological Considerations}

On the theoretical framework of the study: CPA was informed by conviction that things and especially policy discourse must be pulled apart (Troyna, 1994), not only analyzing state mechanisms and policy documents expressing governments' purpose of stating actions and 
intentions to be implemented. However, it is to find whose interests they serve and whose voices were excluded in the policy practice at FSK, 1964-1975.

This study examined secondary school curriculum put in practice at FSK from1964 to 1975. This study was located within Critical Policy Sociology (CPS) an approach to policy analysis rooted in the social science tradition, historically informed and drawing on qualitative and illuminative techniques (Ozga, 1987). The main reason of using critical policy sociology is to understand the methodological approaches that were used to produce education policy text and how it was implemented at FSK.

Ball (1993) distinguishes between policy as a text and policy as a discourse. This study found Ball's categorization relevant to this study because it underlines the general view of postmodernists social analysts that policy intentions are not necessarily translated as they were intended by developers at the micro levels/schools (Baach, 2008; Spillane, 2002 Shapiro, 1993). Indeed, McLaughlin (1987) discovered that implementers often reacted contrary to what policies instructed and at times resisted the policies. As a result, the discrepancy between theory and practice persists in education reform implementation. In an attempt to explain this discrepancy of theory and practice in curriculum reforms, Spillane (2008) claims that implementation of policy involves interpretation and figuring out what a policy means and whether, and how it applies to the implementers' specific context. Answers to these questions enable implementers to adapt, adopt, or ignore a particular policy during implementation process. The study employed Critical Policy Archaeology (CPA) postulated by Trevor Gale in (2001) to explore whether actors enacted policy as intended by the policy maker or acted contrary to what policy maker had intended at FSK.

\section{Critical Policy Enactment Conceptual Framework}

This framework is critical policy standpoint in which policy enactment evaluates where policies are contested and resisted, suppressed or enforced as well as examining particular context of policy implementation (Braun, et al., 2011). There are two approaches to policy analysis: policy- as- written and policy- as- practice.

Policy- as- written focuses on documents and other texts which policy makers communicate their intent (Sutton \& Levinston, 2001). While policy- as- practice is interpretive and decisionmaking process which take place in schools and classrooms and results in standards at a site (Sutton et al., 2001). Thus, critical policy analysts who focus on enactment view policy as practice.

In the context of education reform, policy may evoke thoughts of national mandate and laws, but the actual implementation by teachers at school is important. The study utilized (Ball, Maguire and Braun, 2012) Critical policy enactment conceptual tool to analyze policy enactment at FSK. This framework embodies the practices within schools, where teachers and principals are viewed as policy makers both in construction and interpretation phase of a policy cycle.

Policies as discursive formations are characterized in Foucauldian manner by gaps, voids, absence, limits and divisions (Foucault, 1972:16). That is, analytic use of context to understand policy enactment is grounded on the diverse variables and factors (the what) and dynamics of context (the how) that shape policy enactment, with contextual dimensions as follows: Situated contexts; professional cultures; material contexts; and external contexts (Ball, Maguire and Braun, 2012:21) of FSK.

In addition, the study adopted historical thinking conceptual framework as guided by Seixas, (2006) because our study is historical. The concepts provide a means of analyzing and 
interpreting historical data derived from primary sources which entails historical interpretation, moral dimension, modernity, and change (Seixas, 2006). The historical significance of phenomenon is what makes people care about certain events, trends and issues today. This makes it prudent for the researcher to use the same conceptual argument to address the implementation of secondary education curriculum at FSK, 1964-1975.

\section{Materials and Methods}

The concept of historical thinking also emphasizes the use of primary sources in establishing historical occurrences and truths. This helps in the corroboration of evidence with secondary sources in a bid to contextualize historical truths. It also assesses what has changed and what has remained the same. Moreover, the framework highlights the importance of recognizing and responding to continuities between the past and the present. Such continuities result from macro and micro-level influences of curriculum reforms. That is, from a modernist perspective/ top-down process, individual institutions reveal the interconnectedness of history. For these reasons, historical concepts provided a basis for shaping, interpreting, and analyzing the existing curriculum implementation in Friends School Kamusinga, 1964-1975

This study adopted historical research method to unearth and classify historical facts and realities of the phenomenon in question. To gain background and perspectives on historical research methodology, methods, and archival research, as they relate to this research, the study was guided by the works of the following authorities: Collingwood (2010; Gottschalk (1969); Golder (2000); Tosh (2006); Scott (1990), Key aspects of these authorities and works are interwoven into the methodology discussed in this study.

Borg and Gall (1989) define the historical method as a systematic search for documents and other sources which contain facts relating to the historians' questions about the past. Similarly, Sutter (2006) defines historical research as the collection of documents and artifacts related to past events, often including a description of patterns or trends in an attempt to explain a phenomenon. Historical research method can be described as the systematic collection and evaluation of data to describe and explain events that occurred sometime in the past.

Historical research provides insights into educational issues that cannot be gained by any other technique (Collingwood, 2010). Historical research is the systematic and objective location, evaluation of evidence to establish facts and draw conclusions about past events. Historical research uses data from personal experiences, observations of others, analysis of documents, records, and artefacts. It leads to a new understanding of the past and its relevance to the present and the future and enables solutions to contemporary problems.

Despite the merits above, it remains probably the most difficult type of educational research (Sifuna, 1995). The study depended much on both primary and secondary sources of data because it focused its inquiry into the past. Primary sources refer to those who have had some direct physical contact with the events being reconstructed and eyewitness accounts of an event (Sifuna, 1995; Gottschalk, 1969). These included: eye-witnesses, Reports, educational reports, KIE papers/reports, and syllabuses, schemes of work, exam records, school records, letters, memos and school Inspections Reports of FSK.

The historical documents were found in the Kenya National Archives (KNA), Kenya Institute of Education (KIE), school archives/libraries, and education institutions. The primary records that were obtained at Friends School Kamusinga were: examination records, admissions, lists of teachers, BOG\& staff meeting minutes, and student lists. They also included oral 
testimonies or interviews from former Head teachers, Teachers' and Students who interacted with the policy in the period.

The study also sourced information from secondary sources which did not bear a direct physical relationship to the events that was investigated. They included textbooks, articles, journals, magazines, newspapers and electronically stored material on the internet. Secondary sources are not only inaccurate sometimes, but they also tend to dispute some facts (Gottschalk, 1969). Hence used to supplement and check on any errors reported in oral interviews. The researcher purposively selected Friends School Kamusinga an institution to participate in the study. The snowball, sampling technique was adopted to select participants to be interviewed since they interacted with the curriculum that was being provided in the school, 1964-1975.

Snowball sampling approach was used to select the sample for the study (Creswell, 2007). This helped in identifying informants such as head teachers, teachers, and former students of Friends School Kamusinga. The study sampled 2 head teachers, 4 teachers, and 6 former students of Lugulu Girls' High School, making a total of 12 participants. They were selected based on their interaction with the curriculum between 1964 and 1975. Data collection procedures adopted were documentary reviews, interviews, videotaping, and email interviewing. In regard to this, the researcher recruited participants via phone calls to book the informants for availability, and then held face-to-face meetings with them at the workplace, homes, business premises, and places where they would be comfortable.

For data analysis, historians accept a primary obligation to check their assertions against data. This is largely based on evidence that is open to public scrutiny and criticism by reexamination of their respective records (Golder, 2000). In this study, the researcher compared data from oral interview data and concluded the findings in each question based on the objective that this paper has explored. Data was organized chronologically from 1964 and 1975. Information obtained from the archives were analyzed and interpreted within the context of the study. The evidence and conclusions of the research findings were presented. The researcher faced certain limitations in this study. These were: necessary information could not be accessed because they were either thrown away destroyed or were sent to Education Offices. Others may have been burnt during the facelift of buildings. However, the researcher endeavoured to access as much information as possible from the available sources. Again, the aforementioned limitations compelled the researcher to elicit more information from the participants. This implied intensive interview and engaging the participants in probing questions.

\section{Findings of the Study}

\section{Previous Research on enactment of Ominde Commission Report}

To put this study within academic and historical context, it is cardinal to present previous studies and literature that exist in regard to the OEC. Mosoti (2011) argues that Ominde Report proposed the setting up of the Kenya School Equipment Scheme (KSES); saw an improvement in the delivery of education in Secondary Schools. Thus, KSES was responsible for supplying essential teaching and learning materials such as chalk, Textbooks, Exercise books, Wall maps, geometrical sets, dividers, compasses, protractors, geographical globes, world maps, rubbers, rulers, pencils.

Anderson (1970) found out that the Ominde Commission led to the provision of more secondary school opportunities through "Harambee" or pulling together (GOK, 1964). These schools later outnumbered government-aided secondary schools in seven out of eight 
provinces. By 1970 there were 498 unaided to 331 government-aided secondary schools. Ominde Commission recommended that the government gets fully involved in all matters of education in line with the constitutional changes after independence. The constitution made the government responsible for all sectors of education. Still, Anderson (1970) asserts that in 1967, the government enacted the TSC Act to manage the training, recruitment, remuneration and disciplining of teachers in the country. In 1968, the government enacted the Education Act,

Ojiambo (2009) supports the recommendations of Ominde Report that it outlined what education had to do after independence". It was a blueprint that laid the foundation of postindependence education in Kenya. Its mandate was to survey and advice the government on the formation and implementation of required national policies for education (GOK, 1965a). The independent Government was mandated to develop education as a vehicle of national development and national unity in Kenya.

On the teacher Education, Ominde Report 1964, felt that Unqualified Teachers and UT's, have low morale in the teaching profession due to poor pay and poor working conditions. This could hinder the achievement of educational goals. The Report recommended in-service training for primary school teachers and that primary school graduates should not be recruited as untrained teachers. However, findings in this study show that there were more UT's in both primary and secondary schools. The UT's outnumbered the trained teachers in secondary schools in Kenya. Bogonko (1992) found out that the Ominde Commission recommended that there was still need for secondary schools to rely on foreign teachers from Europe and the USA. The Commission appreciated their role and continued support. According to the GOK (1964), the Ominde Report was set up to achieve the following objectives or purpose after independence: Ten objectives of Education in Kenya were submitted by the commission in 1964 were: fostering of nationhood and promoting national unity; serving the needs of people without discrimination; using schools as the instrument of the state; Respecting cultural traditions of people in Kenya; respecting cultural traditions of people in Kenya; respecting cultural traditions of people in Kenya; using education as a means of producing a conscious change of attitudes and relationships in preparation for the modern world; Fostering respect for human personality; serving the needs of national development; training in social obligation and responsibility; and, preparing students so that they can adapt to change.

Njoroge (1972) applaud Ominde Education Commission by analyzing the set goals of education. He explains that education was believed to be the central agent of social change, promotion of national unity and national development after independence. However, some set goals of education contradicted some basic values that the British had perpetuated during the colonial period. The format of education in the newly-independent Kenya emphasized on corporation and unity, rather than British values of rigid competition and individual achievement. In addition, Njoroge (1972) further states that, after independence, ethnicity caused disunity in Africa and Kenya in particular, which eventually negatively influenced curriculum implementation in the country.

In addition, Njoroge (1972) points out that the Ominde Commission Report did a thorough job of surveying the educational resources. It also provided general guidelines for future policy concerning issues such as equipment, school buildings, and distribution of teachers, teacher training and management of schools. On the critical priority areas, such as the restructuring of the curriculum and the whole educational machinery, qualitative and 
quantitative expansion, and the speed with which some of the crucial problems had to be tackled, the report failed to provide the course of action to be taken.

Sifuna et al. (2014) argues that Ominde Education Commission led to the expansion of education access in the early years of independence in Kenya. It advocated for the replacement for expatriate personnel in the education sector. This was precipitated by political independence, localization of positions in the civil service and curriculum. Secondly, the Kenya Government and the UK requested the World Bank to take part in financing educational issues in the country. This would hasten development in the independent Kenya. The Ominde Education Commission also recommended for improvement in teacher training strategies.

Further, a study by Sifuna, et al (2014); Furley (1972) found out that politics also influenced education reforms and education expansion and this hampered the Ominde Education Report. The expansion and reforms in the education system were motivated by political pressures, where politicians and election manifestos leading to independence elections, called for more educational opportunities of all types, cheaper or free education, Universal Primary Education (UPE), Africanization of syllabus and teaching staff as well as a change in the atmosphere in which the African personality and culture could flourish.

However, OEC was criticized to have failed in achieving its objectives. The system was mainly criticized for lacking the capacity and flexibility to respond to changing aspirations of individual Kenyans. This was in terms of new skills, new technical skills, and the attitude to work. As a result, the problem of unemployed educated youth and school leavers became evident in the country. This is supported by a study by Owino (1997) who explains that failure reported concerning on the OEC led to the nationwide call for reforms in the curriculum. This led to the proposal of a new curriculum to replace that of OEC that had been in place from independence. From the foregoing, most of these studies examined general analysis of recommendations by Ominde Report 1964/65 and how they influenced the development of education in Kenya in the post independent period.

\section{Kamusinga School Enacting the Ominde Commission Curriculum Subjects and Courses Taught at FSK}

Secondary school subjects implemented at Friends School Kamusinga between 1964 and 1975.The participants were asked to present their views on what curriculum they implemented at FSK. Several teachers stated curriculum was 7-4-2-3, meaning they had challenges, hence impacted negatively on the implementation of curriculum at Friends School Kamusinga. This implied that teachers never understood what curriculum policy was. Hence, undermined their efforts to effectively implement curriculum as expected by policymakers. Upon the establishment of the school in 1957, the curriculum/ subjects were: English language and literature/Arithmetic, Algebra, Geometry, and Trigonometry, History, Geography, Agriculture, Biology, Physics- with- Chemistry and Swahili. The findings were also found to be in agreement with the assertions of Bradley (1987).

There were also developments in curriculum reforms about subjects learned. All the 2 head teachers, 4 teachers, and 6 students who participated in this study unanimously agreed that there were subjects implemented between 1964 and 1975. These were: English Language, Literature in English, Swahili, Physics, Chemistry; Biology; History, Geography, Religious Instruction, General Science and Physics -with- Chemistry in " $O$ " level. The documents analyzed during this study show that there were a number of subjects implemented at Friends 
School Kamusinga. These were: English Language, Literature in English, History, Geography, Swahili, Mathematics, Physics, Chemistry, Biology and Physics-with-Chemistry.

The findings of the study also established that besides implementing secondary school curriculum at Friends School Kamusinga, the implementation was categorized into two courses. These were: the Ordinary level ("O" Level) curriculum and Advanced level (" $A$ " Level) curriculum. For " $O$ " Level, the following subjects were taught: English language and Literature in English, Swahili, History, Geography, and religious instruction, Physics- with-Chemistry, Biology, Physics, Mathematics, Music and Physical Education. " $A$ " level classes of both Arts and Science subjects. Arts subjects included Geography, History, Swahili and General paper while Science subjects included Mathematics, Physics, Biology and Chemistry.

Table 1: The Secondary School Curriculum of FSK in 1973.

\begin{tabular}{lll}
\hline \multicolumn{3}{c}{ Subjects of “A” and “O” levels, 1973} \\
\hline $\mathbf{2}$ & English Language & $\mathbf{7}$ Mathematics \\
$\mathbf{2}$ & English Literature & $\mathbf{8}$ Physics \\
$\mathbf{3}$ & History & $\mathbf{9}$ Biology \\
$\mathbf{4}$ & Geography & $\mathbf{1 0}$ Agriculture, current affairs \\
$\mathbf{5}$ & Swahili & $\mathbf{1 1}$ Art \\
$\mathbf{6}$ & General paper & \\
\hline
\end{tabular}

Source/M's letter to PIS, staffing List, dated June, 1973.

FSK also expanded their curriculum to include new subjects from 1968 to 1975 . Further, by 1968, there were 10 subjects in the school curriculum. However, Religious Studies and General Science did not attract any student in 1973, although the subjects increased from 08 to 13 for both "O" and "A" levels.

\section{Traditional and Cultural Orientation in Curriculum Implementation}

The findings revealed that there were school traditions, colonial culture and traditions that influenced curriculum implementation at FSK. Between 1964 and 1975, secondary education championed by OEC was geared towards serving the interest of the European imperialism. This is because, the subjects taught aimed at covering the British Curriculum. This is also in line with the assertions of Gale (2001). However, immediately after independence, especially between 1964 and 1965 the curriculum continued to serve foreign interests and values. The curriculum that was implemented at FSK from 1962 to 1973 appeared to have borrowed a lot from the British "O" level curriculum.

In regard to school tradition, one participant had this to report:

"Both my days as a student, the school tradition, was moulded on the ethos of 'selfdrive and the common sense' where the community members of the school adhered to this tradition. The curriculum was broken into basic standards and implemented at House, Class, club/society and individual levels which led to high academic achievement in school." 


\section{Assessment of Curriculum}

The findings of the study confirmed that examination bodies influenced what was taught, how it was taught, and ways of assessment of the curriculum in secondary schools like FSK in Kenya. The Cambridge Local Examinations Syndicate (CLES) established in 1964 was mandated to be the examining body. It served until 1969 and then E.A.E.C was established, to administer national assessments in Kenya. East African Examinations Council (EAEC) was established by three independent states of East Africa. These included Kenya, Uganda and Tanzania. EAEC handled secondary education curriculum matters, including evaluation of curriculum from 1969 to 1979. East African Community (EAC) was established by the Arusha Declaration in Tanzania in 1967. When the EAC collapsed in 1977 following political issues caused by ideological differences, the EAEC also collapsed. The study found out that even with the creation of the East African Examinations Council, and KNEC, the British models and methodologies still influenced courses and subjects taught during this period. This finding concurred with Bagunywa (1980), who argued that in the first ten years in Africa and particularly Uganda, all subjects, courses, formulation of examination questions, and assessment were determined by the Cambridge syndicate of the United Kingdom in London. The findings also indicated that there was an examination which was done at the end of Form Two which was known as the Kenya Junior Secondary Education (KJSE). The same was also implemented at FSK within the study period. Report of the (KJSE) Subjects is shown in Table 2 below.

Table 2: K.J.S.E Subjects at FSK, 1967

\begin{tabular}{llll}
\hline & Subjects & No. of Students & Percentages \\
1 & English & 10 & 16.66 \\
2 & Swahili & 10 & 16.66 \\
3 & Mathematics & 10 & 16.66 \\
4 & General Science & 10 & 16.66 \\
5 & Biology & 00 & 00 \\
6 & Geography & 10 & 16.66 \\
7 & History & 10 & 16.66 \\
& Total & 60 & 100 \\
\hline
\end{tabular}

Source: KJSE Result analysis, 1967

\section{Influence of British Curriculum on OEC}

The curriculum which was implemented at FSK and other secondary schools between 1964 and 1975 was the formalization of British education curriculum, models and methodologies. This implies that Western values were perpetuated implicitly by the neocolonial education system, because the first decision-making institutions in education in Kenya such as KIE, MOE, EAEC and KNEC did not radically shift from British values unlike in Tanzania after Arusha Declaration (Lillis, 1985; Bagunywa, 1980). The study revealed that the British curriculum continued influencing education reforms during the entire first decade of the independence in Kenya. 


\section{School Management and Physical Facilities}

The study established that organized management of FSK culminated into effective curriculum implementation. Thus, there was strong internal departmental organization in subject areas. Teachers were effectively supervised by head teacher, deputy head teacher, senior master, and the head of the department (HOD). The HOD facilitated the provision of teaching materials and as well ensured that the syllabus was adhered to. The HOD also ensured teamwork and team teaching, marking, administration of exams, and revision of tests.

\section{Challenges in Curriculum Implementation}

There were few challenges in the implementation of curriculum at FSK. One of the key challenges was the shortage of teachers who specialized in the teaching of history, Swahili; Art \& Craft were hard to come by. Consequently, these subjects were negatively implemented between 1964 and 1973. The teacher shortage led to the hiring of foreign expatriate teachers whose academic qualifications were questionable. These foreign teachers negatively influenced the implementation of curriculum reforms negatively in Africanization of education and the civil service (Bogonko, 1991). This featured in the way in which they pronounced certain words coupled with British accent. This again led to confusion on many students and lack of interest in the concerned subjects. This posed a negative influence on curriculum development and its final implementation at FSK.

The other challenge was that there was continuity of British subjects' content/curriculum, values, and language in the curriculum. The participants also indicated that challenges facing secondary school education in Kenya was due to colonial legacy. This implies that in the period the study, from 1964 to 1975, much of what was taught in the curriculum in Kenya was influenced by British education system and its related ideologies. Hence this study argues that education which was recommended by Ominde Report and enacted at FSK compromised inculcation of African heritage and values through learning.

\section{Discussions}

The discussions presented in this section are based on the study's findings. The subjects offered at FSK, "O" Level were: English language and Literature in English, Swahili, History, Geography, and religious instruction, Physics- with-Chemistry, Biology, Physics, Mathematics, Music and Physical Education. "A" Levels were: Geography, History, Swahili and General paper while Science subjects included Mathematics, Physics, Biology and Chemistry. Tradition of FSK influenced students' attraction and interests towards Science and Arts subject at FSK. This outcome of the two subject clusters benefited individuals, the school community and the country at large. However, General Science and Religious studies attracted no students at the school (FSK) in 1968. Instead, the boys of FSK were attracted to Mathematics and science at the inception of the secondary school curriculum in Kenya.

Curriculum implemented after Ominde report in 1964, was not relevant to the Kenyan needs after independence, 1964-1975. This study posits that, there is a general criterion which characterize a relevant curriculum as noted by scholars such as Sousa, 2008; Silva, 2006 and Paolo Friere (1985) believe that a relevant curriculum enables learners ascribe to their historical past, learn from her or his culture, respect others and connect new knowledge to their living experiences. From the findings and explanation of relevance as discussed by critical scholars, the subjects/curriculum reforms enacted at FSK, 1964-1975 does not meet the criterion. Hence, there was need for subjects to be designed in line with the needs of the 
society. Thus, MOE should be thorough in doing this, so that areas that are taught address needs and dynamics of life and society in general.

On traditions and cultural orientation, school tradition was instrumental to facilitate academic prowess and curriculum implementation at FSK. The head teacher and style of leadership in the management of school affairs were also found to influence curriculum implementation. For instances, where the head teachers were firm, decisive and managed their staff better, there seemed to be a better implementation of the curriculum. This is a clear indication that there were established set regulations and rules that acted as roadmap towards academic achievement of the school. The curriculum implemented at FSK was a continuation of colonial education in the post-independent Kenya. This proved that there were continuity and change of subjects that were implemented during the colonial period between 1957 and 1963, and those that were implemented from1964 to 1975.

Curriculum implemented at FSK between 1964 and 1975 represented European values. In addition, the curriculum was a replica of the curriculum of English Grammar School of UK (EGS). Also, subjects implemented at FSK were similar to that of the British curriculum, values, and methods. The secondary school curriculum also represented foreign values and interests at the expense of those of Kenyans. This means that what was taught at FSK, in Kenya did not reflect African values, but was influenced by the OEC which still emphasized British culture and values. This was quite detrimental to one of goals of education in Kenya which aimed at influencing the learner to embrace cultural heritage. The findings were supported by Eshiwani (1993) that, as the political aspect shifted after independence, the education system also shifted and was modelled from the British colonial education system.

On school management and physical facilities, availability of physical facilities like laboratories and libraries enhanced successful curriculum implementation. There were well-trained teachers who made sure that curriculum was professionally implemented. However, teacher shortage was a great concern immediately after independence in 1963 . The secondary education had a shortfall of teachers because this sector had been neglected during the colonial period since the colonizers did not develop secondary education for Africans (Lillis, 1985).

Thus, at the time of independence and thereafter, there were inadequate teachers to teach in secondary schools in Kenya. The challenge of teacher shortage in the first decade of independence has become a perennial problem in the country to date. This challenge of teacher shortage has hampered effective curriculum implementation in Kenya since independence. In this regard, there is dire need for the government to ensure that the problem of teacher shortage is effectively sorted to enhance quality education and effective curriculum implementation.

The other challenge encountered at FSK was political intrusion. Politics played key role in influencing curriculum reforms. There were always political dynamics in curriculum policy construction and implementation. Politics had played a major role in Kenyan society and affected every area of policy-making and implementation. The findings were in tandem with assertions of Wanyama \& Changa'ch (2013). This implies that politics should not be allowed to influence affairs of academics for quality outcome in the education sector.

As expressed by head teachers and teachers interviewed, teachers lacked power and voice on the content or subjects that were enacted at FSK and in other secondary schools in Kenya. This calls for top stakeholders in the education sector to find ways of engaging teachers from initiation of curriculum development to implementation stage. The teachers interviewed also expressed their concern that the OEC rushed the curriculum reform and implementation. 
Within this understanding, they sounded a warning to the government not to rush the newlyproposed curriculum, the CBC.

\section{Conclusions}

The study concludes that education system proposed by OEC was implemented at FSK and other schools in Kenya. The implementation was a continuation of the colonial British curriculum fashioned towards European culture and values. The development and implementation of the curriculum was a top-down policy which excluded teachers and parents. Even after Kenya's independence, neocolonialism continued to influence education system in the independent Kenya.

\section{Recommendations}

Based on the findings of the study recommends that there is need to improve our curriculum policy (but caution should be taken especially with imported education policies and ideologies/values. Even when policies are culturally relevant, locally mediated and recontextualized, the result of transfer remains unpredictable (Beech, 2006). This study recommends that the government should thoroughly invest in researching on curriculum policies to determine their suitability rather than adopting foreign ones which could be irrelevant to the society needs. Thus, before embarking on reforms, empirical studies should be carried out on the existing policy to provide insights for the new reform. This should involve piloting, training, and evaluation. The implementation of the policy should be based on school context or bottom-up instead of top- bottom to allow participation of other stakeholders and more particularly teachers. Teachers should be allowed to air their views regarding any given new curriculum or, in the event of reviewing the existing one, for relevance in addressing emerging issues. Its success is rooted in the decisions and practices of the teachers enacting target policy. This is because teachers are the ones who enact policies. Therefore, their voice; work experiences, and values should be considered.

\section{References}

Amukoa, W. (2013) 'A Call to Reform Secondary Schools in Kenya.' American International Journal of Contemporary Research, Vol. 3 No 1: January 2013

Amutabi, M. N. (2003). Political interference in the running of education in postindependence Kenya: A critical retrospection. International Journal of Education development 23:141.

Bagunywa, A. M. K. (1980). Critical issues in African Education: A case of Uganda. (2nd Ed) New York, NY: Alfred. A Knopf.

Bogonko, S. N. (1992). History of modern education in Kenya, (1895 - 1991). Nairobi: Evans Brothers (Kenya) Ltd.

Borg, W. R., \& Gall, M. D. (1989). Educational research. An introduction (5thed), New York, NY: Longman

Bradley, A. (1987). One Man's Education. An Autobiographical Scrapbook. York: William Sessions. Bungoma Annual Report (1964).

Cohen. L., Manion, L., Morrison, K. (2007). Research methods in education (6thed)

Collingwood. (2010). The Principles of History and Other Writings in Philosophy Of History. March 21 April 3, 2010.

Creswell, J. W. (2007). Qualitative inquiry and research design. Choosing among the five approaches (4th Ed), thousand oaks CA Sage. 
Eshiwani, G. S. (1993). Implementing educational policies in Kenya. World Bank Discussion Paper No. 85. Washington D.C: World Bank.

Furley, O. W., \&Watson, T. (1978). A History of Education in East Africa. New York: N.O.K. Publishers.

Gale, T. (2001). Realizing Policy: The who and the how policy production, in Routledge Falmer reader in education policy and politics, Routledge, London, UK.

Gottschalk, L. (1969). Understanding history: A primer of the historical method Kampala. EAP House.

Kombo, D., \& Tromp, L. (2006). Proposal and Thesis Writing. An Introduction. Nairobi;

Lillis, K. M. (1985). Expatriates and the processes of secondary Curriculum innovation in Kenya, (D. Phil. Thesis, University of Sussex). New York, NY. Routledge.

Mosoti, Z. (2011). Human resource development (HDR) through technical and vocational Education and Training (TVET) during independence days in Kenya. International Journal of Social and Policy issues, Vol 8, No. 2 by the development Universal Consortia.

Nabiswa, M. W. (1999). The Role of the Friend mission in the Development of secondary Education in Western Kenya. The Case Study of Friends school Kamusinga,1950-1985. (unpublished) M.ED. Thesis. Kenyatta University, Nairobi

Njoroge N. (1972). An Outline of Historical Development of Primary Education in Kenya, 18441970. (Master's Thesis Ohio University).

Ojiambo, P. O. (2009). Quality of education and its role in national development. A case study of Kenya's educational reform, Kenya studies review vol 1 (1) pp133 - 149.

Owino, C. (1997). Vocational education in primary schools in Kenya and Tanzania: A comparative study with special reference to Kenya [Unpublished MA dissertation]. Moi University

Patel, S. (2015). The Research Paradigm, Methodology Epistemology and Ontology explained in simple language. Retrieved from http://salmapatel.co.uk/ academic/ the research paradigm- methodology- epistemology-and-ontology-explained- is- simple- language.

Peter, N. G. (2000). Historical Method in Marketing Research with New Evidence on Long Term Market Share Stability: Journal of Marketing Research Vol. XXXVII (May-2000), 156-172

Seixas, P. (2006). Benchmarks of Historical Thinking. A framework for Assessment in Canada. UBC.

Sifuna, D. N., \& Oanda, I. (2014). Historical and Contemporary Trends in the Development of Education in Kenya: Government Policy, Gender and Regional Dimensions: Nairobi, Jomo Kenyatta Foundation.

Sifuna, D. N. (1995). Development of education in Africa: The Kenyan experience. Nairobi. Initiatives and publisher Ltd.

Sutter, W. N. (2006). Introduction to Educational Research. London: Sage Publications, Inc.

Wanyama, P. M., \& Changa'ch, J. K. (2013). Education Reforms in Kenya for innovation. Journal for International of humanities and social sciences. Vol 3 no. 9 pp 123-145

Woolman, D. C. (2001). Educational reconstruction and post-colonial curriculum development: A comparative study of four Africa countries. International Education Journal, 2 (5), 27-46. 